\title{
From Power and Privilege to Dignity and Respect: Developing a Theory of Species Stratification and Interspecies Dominance
}

\author{
Kwan-Lamar Blount-Hill ${ }^{1 *}$ and Paul Oder ${ }^{2,3}$ \\ ${ }^{1}$ Borough of Manhattan Community College, The City University of New York, New York, NY, United States, ${ }^{2}$ The Graduate \\ Center, The City University of New York, New York, NY, United States, ${ }^{3}$ John Jay College of Criminal Justice, New York, NY, \\ United States
}

\section{OPEN ACCESS}

Edited by:

Leslie Cornick,

University of Washington Bothell,

United States

Reviewed by:

Mohammad Imam Hasan Reza, Independent Researcher, Chittagong,

Bangladesh

John F. Organ,

United States Geological Survey (USGS), United States

${ }^{*}$ Correspondence:

Kwan-Lamar Blount-Hill

kblount-hill@jjay.cuny.edu

Specialty section

This article was submitted to

Conservation,

a section of the journa

Frontiers in Ecology and Evolution

Received: 29 April 2020

Accepted: 18 August 2020

Published: 11 September 2020

Citation:

Blount-Hill K and Oder P (2020) From Power and Privilege to Dignity and Respect: Developing a Theory

of Species Stratification

and Interspecies Dominance.

Front. Ecol. Evol. 8:553460.

doi: 10.3389/fevo.2020.553460
Traditional conservation scientists approach conservation conflict from a resourcemanagement perspective, in which both wildlife and non-living natural resources are managed to balance the interests of competing human stakeholders. We instead explore conflict between the powerful and less powerful humans and wildlife alike. Applying tenets of social dominance theory to ecological networks, we propose that socio-political power structures that marginalize human populations - denying voice and inclusion - may contribute to similar neglect of wildlife species. Considering nonhuman species as collections of agentic beings seeking to satisfy their own survival interests and that of their respective "social" group, we connect the subjects of social justice and ecological justice through common challenges rooted in the social psychology of power.

Keywords: human-wildlife conflict, social dominance theory, social identity theory, human-animal relations, conservation social science

\section{INTRODUCTION}

Theories provide frameworks for understanding complex phenomena, crucial for organizing overarching, coherent conceptualizations of the natural and social world. Formally, a theory is "a statement of concepts and their interrelationships that shows how and/or why a phenomenon occurs" (Corley and Gioia, 2011, p. 12). Within social science, theory is especially important as causal chains of human behavior are largely composed of hard-to-measure or unobservable factors requiring a system of assumptions to "fill in the blanks." One way to develop theory is through theory borrowing, the "importation of coherent and fully formed ideas that explain a phenomenon. . . from outside the discipline" (Oswick et al., 2011, p. 319). As conservation sciences increasingly prioritize human dimensions, social sciences provide sources from which to borrow and build a more comprehensive "conservation social science" (Bennett et al., 2017a). Social scientists have already enriched understandings of the human dimensions of conservation. Still, in a review of conservation social science, Bennett et al. (2017b) note a need to more critically examine underlying assumptions about conservation behavior. We propose that applications of social dominance theory to the conservation context holds promise for new perspectives on conservation issues.

\section{HUMAN-WILDLIFE CONFLICT AS SOCIAL CONFLICT}

Sociologist Austin Turk (1966) suggests that conflict relations exist wherever "moves by either (party) open up or block off possible moves" by another toward a more favorable position (p. 343). 
While recent work by conservation social scientists has examined tensions between human groups arising from conservation efforts (Chan et al., 2007), intergroup conflict has long been studied as a catalyst for injustice, animating criminological perspectives like "green criminology" (South, 2014), "conservation criminology" (Gibbs et al., 2010), and "environmental security" (Shearing, 2015). These insights need not be restricted to a purely human context.

Traditionally, human-wildlife conflict (HWC) is defined as individual-level interactions between humans and wildlife that negatively impact the human, the wildlife, or both (Kansky and Knight, 2014). Blount-Hill and Natarajan (2019) instead describe macro-level human-wildlife conflict (MHWC) as conflict arising from large-scale competition for resources between human and nonhuman species. Inspired by studies like Lenski's (1966) on human social stratification, MHWC theorists point to stratification between human vs. nonhuman groups, proposing it as both cause and consequence of sociostructural and psychosocial processes involving perceptions of group superiority. Seeing HWC as competition between groups, sociological perspectives are fertile ground for exploring new models. For this, there is need for coherent theory explaining the psychological mechanisms at the core of HWC. Here, social psychological theories of intergroup conflict may resonate.

\section{INTERGROUP CONFLICT: SOCIAL IDENTITY THEORY AND SOCIAL DOMINANCE THEORY}

According to social identity theory (SIT), people categorize themselves and other social objects (e.g., people, wildlife) into groups (Tajfel et al., 1971). Through identification, we adopt the identity and behavior of groups we belong to. Group membership provides connectedness, self-esteem, and pride, but can also lead to feelings of "us vs. them." According to SIT, people favor their ingroup and disfavor outgroups (Levin and Sidanius, 1999). Social dominance theory (SDT) similarly centers group identification, particularly its role in social hierarchy (Sidanius and Pratto, 1999). SDT theorists argue that societies typically consist of three types of hierarchies: (1) Adults dominate children; (2) men dominate women; and (3) socially-defined groups whose men, women, and children dominate some other arbitrarily defined group (Pratto, 2010). SDT emphasizes that socialization and systemic processes indoctrinate all groups to accept status quo hierarchies, such that these processes - not in group favoritism - drive social dominance.

While neither SIT nor SDT were originally applied beyond humans, nonhuman species are important social actors in human societies. Nonhuman species have been integrated across human societal hierarchies, venerated as sacred (Frascaroli et al., 2014), trusted as companions (Walsh, 2009), relied on as labor (Porcher and Estebanez, 2020), and despised as threats to social order (Pimentel et al., 2001). Generally, humans have regarded themselves as superior to other species and great tensions arise when wildlife interests are seen to be prioritized over those of human groups (Baynham-Herd et al., 2018). As conservation conflict research has highlighted struggles between human groups (e.g., environmentalists and agriculturalists), confrontations between agricultural and pastoral communities and wildlife species are well-documented in HWC studies (Kansky and Knight, 2014). Moreover, animal and plant species are not necessarily passive social actors. Nonhuman species have themselves been noted to display behaviors similar to those outlined in SIT and SDT - from ingroup favoritism observed amongst dolphins and monkeys (Masuda and Fu, 2015) to deferring to established social hierarchies so as to avoid conflict and retaliation (Drea and Wallen, 1999). Studies into animal psychology and behaviors show that species have adapted to respond to humans as members of a common social group (Topál et al., 2005) and as enemies (Smith et al., 2017), with the expected reactions attendant thereto. A comprehensive science of social hierarchy must consider the place of nonhuman biota, including those in the wild.

According to SDT, members of dominant groups more readily embrace the idea of social dominance - this personality trait is called social dominance orientation (SDO). Importantly, SDO has been linked to anti-environmentalism and a view of the natural world as subordinate and subservient to the needs of humanity (Milfont and Sibley, 2014). Legitimizing myths are also key, defined as ideologies "that provide moral and intellectual justification for the social practices that distribute social value within a society," reframing inequality-producing practices as something else (Sidanius and Pratto, 1999, p. 53). Legitimizing myths either enhance hierarchy (e.g., American "Manifest Destiny") or attenuate it (e.g., socialism), but are crucial, either way, for coordinating collective action through collective belief (Pratto, 2010). Ideologies that propagate the notion of nonhumans' inferiority and the heightened value of humankind help to encourage beliefs and behaviors that foreground human desire over the needs of nonhumans (Hyers, 2006).

\section{APPLICATIONS OF SIT AND SDT TO HWC}

We have begun exploring these theories as applied to humanwildlife conflict. At the 2019 International Congress of Conservation Biology, the first author proposed that SDO might underpin human-wildlife conflicts and presented preliminary evidence to support that assertion. He used Stata analytic software and exploratory factor analysis to predict values of a latent factor derived from the Cato Institute's Human Freedom Index, Freedom House's Freedom in the World Index (FITW), and the United Nations' Gender Inequality Index (GII). This factor moderately correlated with the number of mammals "under threat" (UT, i.e. critically endangered, endangered, or vulnerable) by the International Union for Conservation of Nature's Red List $(r=0.41, p<0.001)$. He suggested this latent factor might be a proxy for a society's dominance orientation. That same year, the American Society of Criminology's Division of International Criminology commended his paper showing relationships (i) between the FITW index and number of UT mammalian species 
$(\beta=-0.3667, p=0.001), R^{2}=0.4580, F(12,112)=7.89$, $p<0.001$, and (ii) the GII and number of UT animal species $(\beta=-0.4384, p=0.002), R^{2}=0.4193, F(12,122)=7.34$, $p<0.001$, though the models as a whole still lacked substantial predictive value.

Meanwhile, Dhont et al. similarly apply social dominance theory within social and personality psychology. Dhont's work drew on Costello and Hodson's (2010) Interspecies Model of Prejudice, in which SDO is related to bias against other human groups through dehumanization - that is embracing human superiority over animals and depicting outgroups as more animalistic. In a series of studies, Dhont and others outlined a social dominance human-animal relations model (SDHARM; Dhont et al., 2016). SD-HARM links SDO to speciesism, "the unjustified disadvantageous consideration or treatment of those who are not classified as belonging to a certain species" (Steinbock, 1978; Horta, 2010, p. 243). Dhont et al. (2014) present findings suggesting that speciesism is moderately correlated with ethnic prejudice $(r=0.41, p<0.001)$ through their common relationship with SDO. In subsequent studies, SDO was also correlated with levels of meat consumption and support for animal exploitation (Dhont and Hodson, 2014). Dhont et al. (2016) replicated the findings of Dhont et al. (2014) and found that correlations with SDO linked measures of ethnic prejudice and bias against vegetarians (whose lifestyles may challenge beliefs about animal inferiority).

In short, Dhont et al.'s SD-HARM proposed that "prejudiced beliefs exhibited in both human intergroup relations and humananimal relations are rooted in an ideological preference for group-based dominance and inequality," i.e. SDO (Dhont et al., 2019, p. 772). Additionally, we have argued that dominant human groups socialize both in-group members and subordinate outgroup members to accept a hierarchical valuation of human needs and desires over needs (or desires) of other biotic species and emphasize species hierarchies as ways to deemphasize human group inequality and maintain control over resources - a social identity theory of interspecies dominance. These distinct but similar lines of theory attempt frameworks for explaining the psychological drivers exacerbating the "conflict relation" between humans and wildlife.

\section{FUTURE DIRECTIONS FOR RESEARCH AND CONCLUSION}

As far as we are aware, our work and that of Dhont et al. encapsulates the full body of literature exploring interspecies relations through an explicitly social dominance and social identity lens. At present, available studies on either of these theoretical propositions show moderate-to-weak correlations at best, seeking to explain broad and complex constructs with few and imprecise data points. Still, these exploratory studies nonetheless found statistical correlations that suggest a need for more rigorous examination to determine the true nature of the relationships between social dominance and other constructs important to conservation psychology and ecological outcomes.
The potential for theorization in this space is nearly untapped. Myriad analytical avenues remain unexplored and available for pioneering work related to the social psychology of interspecies dominance. At the individual level, Dhont et al.'s studies utilize only Belgian and American subjects, mostly student convenience samples. As yet, there are no qualitative studies or analyses of "real-world" events supporting their theoretical frameworks. At the nation-level, the first author's analyses have used secondary, imprecise data attempting to measure SDO evinced in national outcomes, though definitive explanations of the relationships found are as yet unclear. Human-focused studies of SDT have neglected levels of analyses higher than the individual, so that cross-national research linking SDO to global species threat necessarily requires innovation in approach and theoretical specification. These challenges are the stuff of novel and exciting science.

We warn that theory borrowing to advance conservation social science will import, with new thought, new controversies contested in their parent fields. For example, SDT originated as at least a partial repudiation of important aspects of SIT and SIT theorists have rebuffed these challenges with pointed critiques of SDT premises (see, e.g., Turner and Reynolds, 2003). Given the early stages of interspecies dominance theories, we have not yet determined the conceptual meaning of these debates for our core hypotheses, much less explored their import empirically. Of course, these too provide areas for study well into the future, perhaps for conservation social scientists. Drawing on the work of green criminologists and others will ensure conservation researchers - particularly those studying human dimensions - have theoretical grounding for new hypotheses. Examples are already found in contributions such as Ryder's (1989; 1999) "painism" and "speciesism," and his critique of utilitarian justifications for animal experimentation (cited in Leuven and Visak, 2013) or works on the ethical implications of biodiversity offsetting (Ives and Bekessy, 2015). At the same time, greater collaboration with natural scientists may well increase empirical support for, or against, social science perspectives. We encourage the growth of cross-disciplinary theorizing and propose theories of intergroup conflict as a starting point. There are infinite relationships that may be explored, but robust and transdisciplinary theorizing can provide structure for directing efforts toward those most promising.

\section{DATA AVAILABILITY STATEMENT}

All inquiries regarding data presented in this manuscript should be directed to the original authors of the studies referenced. Inquiries regarding unpublished analyses may be directed to the corresponding author.

\section{AUTHOR CONTRIBUTIONS}

The perspective reflected in this manuscript represents the collective stance and collaborative inputs of both K-LB-H and PO. Both authors contributed to the article and approved the submitted version. 


\section{REFERENCES}

Baynham-Herd, Z., Redpath, S., Bunnefield, N., Molony, T., and Keane, A. (2018). Conservation conflicts: behavioral threats, frames, and intervention recommendations. Biol. Conserv. 222, 180-188. doi: 10.1016/j.biocon.2018. 04.012

Bennett, N. J., Roth, R., Klain, S. C., Chan, K. M. A., Clark, D. A., Cullman, G., et al. (2017a). Mainstreaming the social sciences in conservation. Conserv. Biol. 31, 56-66. doi: $10.1111 /$ cobi. 12788

Bennett, N. J., Roth, R., Klain, S. C., Chan, K., Christie, P., Clark, D. A., et al. (2017b). Conservation social science: understanding and integrating human dimensions to improve conservation. Biol. Conserv. 205, 93-108. doi: 10.1016/ j.biocon.2016.10.006

Blount-Hill, K., and Natarajan, M. (2019). "Human wildlife competition: exploring human activities, environmental transformation, and mammalian species threat," in Quantitative Studies in Green and Conservation Criminology: The Measurement of Environmental Harm and Crime, eds M. J. Lynch and S. F. Pires (New York, NY: Routledge), 111-126. doi: 10.4324/9780429453946-6

Chan, K. M. A., Pringle, R. M., Ranganathan, J., Boggs, C. L., Chan, Y. L., Ehrlich, P. R., et al. (2007). When agendas collide: human welfare and biological conservation. Conserv. Biol. 21, 59-68. doi: 10.1111/j.1523-1739.2006.00570.x

Corley, K. G., and Gioia, D. A. (2011). Building theory about theory building: what constitutes a theoretical contribution. Acad. Manage. Rev. 36, 12-32. doi: 10.5465/amr.2011.55662499

Costello, K., and Hodson, G. (2010). Exploring the roots of dehumanization: the role of animal-human similarity in promoting immigrant humanization. Group Process. Interg. 13, 3-22. doi: 10.1177/1368430209347725

Dhont, K., and Hodson, G. (2014). Why do right-wing adherents engage in more animal exploitation and meat consumption? Pers. Indiv. Differ. 64, 12-17. doi: 10.1016/j.paid.2014.02.002

Dhont, K., Hodson, G., Costello, K., and MacInnis, C. C. (2014). Social dominance orientation connects prejudicial human-human and human-animal relations. Pers. Indiv. Differ. 6, 105-106.

Dhont, K., Hodson, G., and Leite, A. C. (2016). Common ideological roots of speciesism and generalized ethnic prejudice: the social dominance humananimal relations model (SD-HARM). Eur. J. Pers. 30, 507-522. doi: 10.1002/ per.2069

Dhont, K., Hodson, G., Loughnan, S., and Amiot, C. E. (2019). Rethinking humananimal relations: the critical role of social psychology. Group Process. Interg. 22, 769-784. doi: 10.1177/1368430219864455

Drea, C. M., and Wallen, K. (1999). Low-status monkeys "play dumb" when learning in mixed social groups. Proc. Natl. Acad. Sci. U. S. A. 96, 12965-12969. doi: 10.1073 /pnas.96.22.12965

Frascaroli, F., Bhagwat, S., and Diemer, M. (2014). Healing animals, feeding souls: ethnobotanical values at sacred sites in central Italy. Econ. Bot. 68, 438-451. doi: 10.1007/s12231-014-9290-7

Gibbs, C., Gore, M. L., McGarrell, E. F., and Rivers, L. I. I. I. (2010) Introducing conservation criminology: towards interdisciplinary scholarship on environmental crimes and risks. Brit. J. Criminol. 50, 124-144. doi: 10.1093/ bjc/azp045

Horta, O. (2010). What is speciesism? J. Agr. Environ. Ethics 23, 243-266. doi: 10.1007/s10806-009-9205-2

Hyers, L. L. (2006). Myths used to legitimize the exploitation of animals: an application of social dominance theory. Anthrozoös 19, 194-210. doi: 10.2752/ 089279306785415538

Ives, C. D., and Bekessy, S. A. (2015). The ethics of offsetting nature. Front. Ecol. Environ. 13:568-573. doi: 10.1890/150021

Kansky, R., and Knight, A. T. (2014). Key factors driving attitudes towards large mammals in conflict with humans. Biol. Conserv. 179, 93-105. doi: 10.1016/j. biocon.2014.09.008
Lenski, G. E. (1966). Power and Privilege: A Theory of Social Stratification. Chapel Hill, NC: The University of North Carolina Press.

Leuven, J., and Visak, T. (2013). Ryder's painism and his criticism of utilitarianism. J Agric. Environ. Ethics 26, 409-419. doi: 10.1007/s10806-012-9381-3

Levin, S., and Sidanius, J. (1999). Social dominance and social identity in the United States and Israel: ingroup favoritism or outgroup derogation? Polit. Psychol. 20, 99-126. doi: 10.1111/0162-895x.00138

Masuda, N., and Fu, F. (2015). Evolutionary models of in-group favoritism. F1000 Prime Rep. 7, 1-12. doi: 10.12703/P7-27

Milfont, T. L., and Sibley, C. G. (2014). The hierarchy enforcement hypothesis of environmental exploitation: a social dominance perspective. J. Exp. Soc. Psychol. 55, 188-193. doi: 10.1016/j.jesp.2014.07.006

Oswick, C., Fleming, P., and Hanlon, G. (2011). From borrowing to blending: rethinking the processes of organizational theory building. Acad. Manage. Rev. 36, 318-337. doi: 10.5465/amr.2011.59330932

Pimentel, D., McNair, S., Janecka, J., Wightman, J., Simmonds, C., O'Connell, C., et al. (2001). Economic and environmental threats of alien plant, animal, and microbe invasions. Agr. Ecosyst. Environ. 84, 1-20.

Porcher, J., and Estebanez, J. (2020). Animal Labor: A New Perspective on HumanAnimal Relations. Bielefeld: transcript Verlag.

Pratto, F. (2010). "Social dominance theory," in Encyclopedia of Group Processes \& Intergroup Relations, eds J. M. Levine and M. A. Hogg (Thousand Oaks, CA: SAGE Publications, Inc), 782-785.

Shearing, C. (2015). Criminology and the Anthropocene. Criminol. Crim. Justic. 15, 255-269. doi: 10.1177/1748895815584712

Sidanius, J., and Pratto, F. (1999). Social Dominance: An Intergroup Theory of Social Hierarchy and Oppression. Cambridge: Cambridge University Press.

Smith, J. A., Suraci, J. P., Clinchy, M., Crawford, A., Roberts, D., Zanette, L. Y., et al. (2017). Fear of the human "super predator" reduces feeding time in large carnivores. Proc. R. Soc. B 284:20170433. doi: 10.1098/rspb.2017. 0433

South, N. (2014). Green criminology: reflections, connections, horizons. Int. J. Crime Just. Soc. Democr. 3, 5-20. doi: 10.1558/crit.v11i1.5

Steinbock, B. (1978). Speciesism and the idea of equality. Philosophy 53, 247-256. doi: $10.1017 / \mathrm{s} 0031819100016582$

Tajfel, H., Billig, M. G., Bundy, R. P., and Flament, C. (1971). Social categorization and intergroup behaviour. Eur. J. Soc. Psychol. 1, 149-178. doi: 10.1002/ejsp. 2420010202

Topál, J., Gácsi, M., Miklósi, Á, Virányi, Z., Kubinyi, E., and Csányi, V. (2005). Attachment to humans: a comparative study on hand-reared wolves and differently socialized dog puppies. Anim. Behav. 70, 1367-1375. doi: 10.1016/j. anbehav.2005.03.025

Turk, A. T. (1966). Conflict and criminality. Am. Sociol. Rev. 31, 338-352. doi: $10.2307 / 2090822$

Turner, J. C., and Reynolds, K. J. (2003). Why social dominance theory has been falsified. Brit. J. Soc. Psychol. 42, 199-206. doi: 10.1348/0144666033221 27184

Walsh, F. (2009). Human-animal bonds I: the relational significance of companion animals. Fam. Process 48, 462-480. doi: 10.1111/j.1545-5300.2009.01296.x

Conflict of Interest: The authors declare that the research was conducted in the absence of any commercial or financial relationships that could be construed as a potential conflict of interest.

Copyright (C) 2020 Blount-Hill and Oder. This is an open-access article distributed under the terms of the Creative Commons Attribution License (CC BY). The use, distribution or reproduction in other forums is permitted, provided the original author(s) and the copyright owner(s) are credited and that the original publication in this journal is cited, in accordance with accepted academic practice. No use, distribution or reproduction is permitted which does not comply with these terms. 